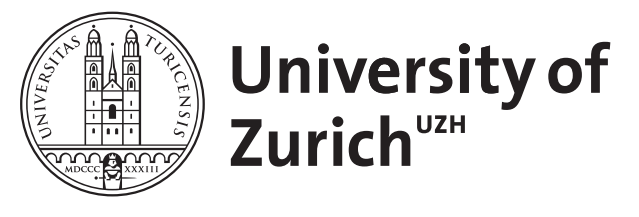

\title{
Loyalty and competence in public agencies
}

\author{
Wagner, Alexander F
}

\begin{abstract}
Competent public agencies are associated with better economic outcomes. Beyond competence, political leaders need to secure the loyalty of their agencies. Unfortunately, several theories predict a tradeoff between these two valued features. This paper finds that recruitment into agencies is meritocratic where (1) agency officials have poor outside options, (2) careers in agencies are long-lasting, and (3) agency loyalty is important. Moreover, agency competence is lower when (4) loyalty is important but the time horizon is short, and (5) outside opportunities improve but the time horizon is long. This evidence fits best with a theory of loyalty as non-contractible behavior.
\end{abstract}

DOI: https://doi.org/10.1007/s11127-009-9587-8

Posted at the Zurich Open Repository and Archive, University of Zurich ZORA URL: https://doi.org/10.5167/uzh-46390

Journal Article

Published Version

Originally published at:

Wagner, Alexander F (2011). Loyalty and competence in public agencies. Public Choice, 146(1/2):145162.

DOI: https://doi.org/10.1007/s11127-009-9587-8 


\title{
Loyalty and competence in public agencies
}

\author{
Alexander F. Wagner
}

Received: 9 December 2008 / Accepted: 17 December 2009 / Published online: 5 January 2010

(C) Springer Science+Business Media, LLC 2010

\begin{abstract}
Competent public agencies are associated with better economic outcomes. Beyond competence, political leaders need to secure the loyalty of their agencies. Unfortunately, several theories predict a tradeoff between these two valued features. This paper finds that recruitment into agencies is meritocratic where (1) agency officials have poor outside options, (2) careers in agencies are long-lasting, and (3) agency loyalty is important. Moreover, agency competence is lower when (4) loyalty is important but the time horizon is short, and (5) outside opportunities improve but the time horizon is long. This evidence fits best with a theory of loyalty as non-contractible behavior.
\end{abstract}

Keywords Public agencies · Political economy $\cdot$ Loyalty

JEL Classification $\mathrm{H} 1 \cdot \mathrm{M} 5 \cdot \mathrm{P} 1$

\section{Introduction}

Loyalty of public agencies to the government (and in particular the prime minister or other head of the government) is valued highly. Anecdotal evidence for the US from Wilson (1989: 198) suggests that agency executives and their staff "are selected in order to serve the political needs of the president, and these may or may not involve policy considerations." Governments are also interested in other types of loyalty, e.g., the absence of bribery and corruption.

Unfortunately, anecdotal observation also suggests that agency loyalty does not always come without costs. For example, the governmental appointment process is frequently regarded as being strongly dominated by considerations of loyalty, at the cost of competence

\footnotetext{
A.F. Wagner $(\bowtie)$

University of Zurich, Plattenstrasse 14, 8032 Zurich, Switzerland

e-mail: wagner@isb.uzh.ch
}

A.F. Wagner

Harvard Kennedy School, Cambridge, MA, USA 
(Edwards 2001). Some argue that this leads to "amateur government" (Cohen 1998). Indeed, Heclo (1977: 99) observed that "many of [the agency's executive's] selectors [are] more interested in the process of getting their way than in the executive's eventual output." If competence of agencies is lower, economic growth and performance will suffer. This appears to be a problem of interest not only in developing countries. For example, some observers worried about the value US President George W. Bush and his administration appeared to put on loyalty. Obviously, this academic paper does not take a partisan point of view. But consider this excerpt from an interview (on November 11, 2004) with Katrina Vanden Heuvel on "Paula Zahn Now," a prime time show on CNN": 1

Zahn: "Let's move on to another controversy brewing in the Bush administration. There are a lot of critics out there suggesting that, in moving the kind of people the Bush administration is into the Cabinet positions, you're doing it not because of competency, but out of loyalty, leading to what they say will be a dangerous group think mentality. Do you see it that way?"

Vanden Heuvel: "Yes. Paula, if competence was an issue here, you wouldn't see any of these people in this administration."

Whether or not one agrees with Vanden Heuvel's response, both Zahn and Vanden Heuvel appear to believe in the premise - that there is a tradeoff between loyalty and competence. This paper studies whether the concern voiced in this exchange is mirrored systematically in evidence on competence in public agencies in a cross-section of countries.

Although the primary focus of the paper is empirical, it is useful to guide the statistical analysis with theory. Recent theoretical research in organizational economics and political economy has unearthed reasons why a tradeoff between loyalty and competence may arise as the optimal solution to an agency problem (Egorov and Sonin 2006; Glazer 2002; Wagner 2006). To test the hypotheses that flow from these and other models, this paper employs a dataset on important state economic agencies (ministries and central banks) in semi-industrialized and developing countries, compiled by Evans and Rauch (1999) and Rauch and Evans (2000). The empirical analysis reveals that governments choose to have highly competent officials in their agencies (as measured by the prevalence of civil service exams for top officials) (1) where officials have few private sector contacts and are less likely to retire to jobs in the private sector, (2) where careers in agencies are expected to be long-lasting, and (3) where the agencies are powerful, i.e., where their loyalty is important. Moreover, competence is lower (4) when loyalty is important but simultaneously the time horizon is short, and (5) when outside opportunities improve but simultaneously the time horizon is long. Although not all estimates are statistically significant in all regressions, overall these findings are consistent with a model of loyalty as a non-contractible behavior along the lines of Wagner (2006), while they are harder to reconcile with or are in contrast to predictions of other theories. As such, to my knowledge, this paper offers the first test of conflicting theories of loyalty and competence. ${ }^{2}$ Additionally, the empirics suggest that a greater extent of political appointment is associated with less meritocratic recruitment. These results are obtained controlling for country variables such how long civil service exams have been in place, human capital (educational attainment), development level (GDP p.c.), and other factors.

\footnotetext{
${ }^{1}$ The transcript is at http://transcripts.cnn.com/transcripts/0411/19/pzn.01.html.

${ }^{2}$ Other work has explored the empirical content of general theories of loyalty. For example, Verwimp (2003) uses the model of Wintrobe (1998) to help in understanding the regime in Rwanda that first aimed to buy political loyalty and then turned to repression.
} 
The question of what factors are associated with greater competence in the public sector is important for the understanding of cross-country differences in economic performance. For example, Rauch and Evans (2000) find that meritocratic recruitment is a statistically significant determinant of ratings by country risk agencies. Evans (1995) argues, following Max Weber, that replacement of a patronage system for state officials by a professional state bureaucracy is a necessary (though not sufficient) condition for a state to grow economically. Evans and Rauch (1999) indeed find that more "Weberian" agencies (including those that have meritocractic recruitment) allow countries to achieve greater economic growth. This paper, thus, takes it as given that greater competence in agencies increases output, and it aims to determine which institutional factors go hand in hand with higher competence in public agencies. That is, it considers the choice of the recruitment mechanism as endogenous. By recognizing that competence can, under some conditions, have a cost, namely, endogenously lower loyalty, the paper also adds to the literature on "new public management" which has, so far, mostly focused on explicit mechanisms like performance-based pay and tournaments as tools for eliciting better performance from agents (Aucoin 1990; Caiden 1988). ${ }^{3}$

The present paper considers the interaction between a central government and its agencies. As such, it is closely related to the important bureaucracy literature in public choice that studies agencies and a sponsor such as a government or a legislature. ${ }^{4}$ A vast literature exists on this subject, and it is impossible to review it comprehensively here. (For a textbook treatment, see Mueller 2003; for surveys, see Wintrobe 1997; Niskanen 2001 and Chang et al. 2001.) One view asserts that the expertise of agencies is superior to the legislature, thus leading to inefficient allocations when the bureaucrat wishes to maximize the budget (Niskanen 1971). ${ }^{5}$ Others have considered a slack-maximizing bureaucracy (Wyckoff 1990). Dunleavy $(1985,1991)$ instead develops the "bureau-shaping" idea according to which bureaucrats want to shape their agency so as to maximize their personal utilities from their work (and not necessarily the budget). All these motivations of agency officials are important reasons why and how the government offers rewards for agency loyalty.

Section 2 begins by reviewing the theoretical background and key predictions. Section 3 describes the data. Section 4 presents the empirical results. Section 5 concludes.

\section{Hypothesis development}

The paper's contribution is primarily empirical. Nonetheless, it is helpful to structure the discussion along some recent theories, in order to be able to derive some specific hypotheses.

\footnotetext{
${ }^{3}$ Using civil service exams as a recruitment tool can, of course, impose significant rent-seeking costs on society. Test-takers will allocate their time and effort away from productive activities in order to master the material on which they will be examined, and educational institutions will teach to the test if they are evaluated on the basis of how many of their graduates pass civil service or other exams.

${ }^{4}$ Other seminal work has considered the economics within agencies. Tullock (1965) formulated a model of the relations between individuals within a bureaucracy, focusing on the advancement and promotion procedures within bureaus. Downs (1967) also considered the management process within agencies, and he also presented an evolutionary or longitudinal premise by tracing the political "life" of a bureau over time, i.e., a life-cycle. An extreme version of the power of the bureaucracy is reflected in Brennan and Buchanan's (1980) Leviathan model, where the bureaucracy and the legislature are one monolithic agent who exploits his power over the citizenry.

${ }^{5}$ The inefficiency is reduced when the sponsor can partially monitor or penalize the bureau and the bureaucrat is risk-averse (Bendor et al. 1985) or when the sponsor can conceal its demand from the bureau (Miller and Moe 1983). See also Makris (2006) for a recent analysis that suggests that the outcome may be more efficient than usually assumed.
} 


\subsection{Basic framework}

Consider a central government that charges an agency with delivering some output. ${ }^{6}$ For the purposes of the present paper and the empirical predictions, we will focus on the government's problem of choosing whom to recruit into the high positions in public agencies. ${ }^{7}$ Let us assume that the government is a unitary actor that can choose the hiring rules for its agencies and that it has some incentive to have agencies provide high-quality service. ${ }^{8}$ For example, agencies with more meritocratic recruitment to the top provide better public goods and allow the economy to grow faster. One way to secure competence in agencies is to require formal exams to enter civil service or at least before entering a high-level position.

Not all of the needs of the government or of the agency executives themselves are covered by having highly able agency officials. Beyond competence, the government is also interested in making sure that agency executives and employees act loyally to the government's needs. Loyalty in this context is taken to mean two things in particular: first, not pushing for policies that are against the central government's plans, and, second, not engaging in illegal side activities. ${ }^{9}$ But both types of loyal actions - voluntarily chosen alignment in policy and minimization of illegal activity - bring (opportunity) costs with them for officials, whether or not the actions are socially efficient. Thus, the government will have to promise rewards, such as support in hard times for the agency, larger budgets, the opportunity to shape the bureau as desired, or an opportunity for agency officers to rise through the government ranks. ${ }^{10}$ This interaction takes place over time. ${ }^{11}$

\subsection{Models of loyalty and competence}

This basic framework can be used to understand the different predictions of various models which I now adapt to the context of public agencies. Unfortunately, because of the very different natures of the existing models (which comprise static and dynamic, complete, incomplete, and asymmetric information sets, and so on), no unified theoretical treatment seems feasible. Instead, I proceed with a verbal discussion of each model and refer to the underlying papers for details.

\footnotetext{
${ }^{6}$ This analysis takes as given the notion that the government decentralizes at least some decisions. See Seabright (1996), Laffont and Martimort (1998), Laffont and Zantman (2002) for discussions on this point. See Borge et al. (2008) for an analysis of the relationship between party fragmentation and efficiency of institutions.

${ }^{7}$ The models presented later also apply within agencies and bureaus and, as such, also relate to the work by Tullock (1965) and Downs (1967). However, data to test the models within organizations are not usually available. See Breton (1995) for a collection of other agency models helpful in understanding "agency within agencies." An especially complex question, neglected here, is ensuring appropriate behavior in hierarchies, i.e., settings with three or more layers. See Tirole $(1986,1992)$ and Vafaï $(2002,2005)$.

${ }^{8}$ Even a government that steals all the agencies' production is interested in their competence. In all but the most autocratic societies, there is also at least some degree of accountability of government, and to the extent that ultimately the government has to fear revolution or being thrown out of office democratically if it does not provide the services its citizens desire, it will maintain a sufficiently high level of agency competence.

${ }^{9}$ As shown in Rijckeghem and Weder (2001), corruption is very hard to eradicate solely by raising wages.

${ }^{10}$ This assumes away intrinsic motivations of bureaucrats and other aspects of motives in bureaucracies. See Wise (2004) for a comprehensive review of work on these issues. In addition, the analysis assumes away monitoring and auditing as key tools of governance within organizations and between. See Baron and Besanko (1984), Kofman and Lawarrée (1993) and Dittman (1999) for formal models of auditing.

${ }^{11}$ Other channels through which the time horizon matters have also been developed. For example, see Konrad and Torsvik (1997) for a model of term limits when information revelation is the economic problem.
} 
Let us begin by considering Wagner's (2006) model. The key assumption there is that both loyalty and rewards are non-contractible and that their exchange thus needs to be sustained through repeated interaction. In trying to induce officials to exhibit loyalty by rewarding them properly, the government faces the problem that more competent agency officials have better side opportunities (some of which are exactly the sort of illegal activity the government wants to prevent). In particular, it is likely that more competent agency officials are better able to find opportunities for accepting bribes. They are more effective at search for side opportunities, they may be able to detect loopholes in the legal system, and they receive more offers because their services are of greater value to those who pay the bribe. Moreover, for a given strength of the contacts between the private and public sectors, more competent officials also have better outside options in the private sector if they are fired or retire. Both observations imply that more competent officials have a more attractive reneging path and are, therefore, less easily induced to foregoing their preferred choice of independent (disloyal) action, be it their own preferred policy or illegal side activities. This makes it difficult to sustain loyalty with highly competent officials. Several predictions for the government's choice of the level of competence of agency officials follow from this model:

\section{A. Competence is lower where there are better side opportunities (illegal activities or private sector options).}

The reason is that when more side opportunities are available, competence is even more productive outside, making loyalty harder to obtain with high competence, thus leading to a decrease in optimal competence for a desired level of loyalty.

\section{B. Competence is higher where public sector careers are expected to last longer.}

Competence will be higher if individuals are more patient, because a self-enforcing contract such as loyalty becomes more easily sustainable over time.

\section{Competence increases as the value of loyalty increases.}

This last prediction is at first surprising. It arises in Wagner's model because the greater the value of loyalty to the principal, the more credibly he can promise rewards. If, by contrast, loyalty generates only a small surplus, the government can only promise rewards that suffice to induce less competent staff and executives to behave loyally.

The theoretical model also has predictions for interaction terms.

D. The interaction between side opportunities and length of expected interaction reduces competence.

\section{E. The interaction between the value of loyalty and length of expected interaction increases competence.}

The logic behind these two predictions is the following. When the duration of interaction is longer, competence is, ceteris paribus, higher (prediction B). According to prediction A, as side opportunities become greater, the deviation temptation becomes greater, decreasing optimal competence. Thus, with a long duration of interaction, the detrimental effect of an increase in side opportunities is larger than if competence is already relatively small (which is the case when the duration of interaction is short). The opposite holds for the value of loyalty.

Another directly relevant and intuitively appealing model of loyalty and competence is Egorov and Sonin (2006). In their model, more competent viziers are more prone to treason. The reason is that they are better able to discriminate among potential plotters, making them more risky subordinates for the ruler because the ruler has to fear that the better informed advisor misinforms him. Therefore, dictators may prefer incompetent viziers. Incentive schemes by the dictator find limitations in the likelihood that the government itself 
remains in place. The authors finetune their model to the context of dictatorships, but they also discuss its assumptions and implications relative to the other papers mentioned here. Indeed, the basic insights apply to the relationship between a central government and an agency; or even more generally to any organization where the center has agents that may try to usurp the central power through misinformation. Egorov and Sonin predict that where loyalty is more important (in the terminology of their paper, where the stakes are high for the dictator), the agent should be less competent. As discussed above, Wagner's model instead suggests that more valuable loyalty makes loyalty more easily implementable even with competent agencies, leading to a positive correlation between the value of loyalty and competence. Egorov and Sonin's second main result is that the principal's commitment ability in terms of being able to threaten capital punishment for a revolutionary vizier determines optimal vizier competence. This result is similar to the prediction of Wagner's model that the expected length of interactions increases optimal competence. Egorov and Sonin's theory does not speak to the role of side opportunities.

In Glazer's (2002) model, an owner of an organization wants a worker to engage in producing benefits for his firm ("external rent-seeking" in Glazer's terminology), but is worried that the worker instead focuses on internal rent-seeking. Again the model is sufficiently general to apply to the present context. Glazer finds that an employer will hire better staff the stiffer the competition for external rents. The primary prediction that distinguishes his model from Wagner's is that in Glazer's analysis the larger the assets subject to rent-seeking (i.e., the more important loyalty is for the owner), the smaller is the desired quality of staff. On the other hand, the model is also different from Egorov and Sonin's world because commitment ability does not play a role; Glazer's approach thus has no predictions for the effect of the discount factor on optimal competence. Finally, Glazer's model also yields no predictions for the role of side opportunities. ${ }^{12}$

A final alternative (which is so simple that no one seems to have bothered with writing it down) would be a static multi-tasking model where more competent officials again have better side opportunities but where these can be part of a contract. Only prediction (C) could follow from a contractible loyalty model. Predictions (B) and (E) do not arise in this static framework. Without further complications, such a model also does not yield a relationship between the available side opportunities and competence (predictions (A) and (D)). The labor market would price competence into the wage offered to an agent, making the participation constraint of the agent more binding. The ultimate effect is that competence is irrelevant for the principal, after deducting the costs of employing a more competent agent.

In the light of these analytically plausible, but partially conflicting or complementary predictions, it is an empirical question as to which theory can best explain the available evidence. $^{13}$

\footnotetext{
${ }^{12}$ Glazer's model does have interesting testable predictions for the effect of the owner's competence on the worker's competence, but to test these would require information about the ability of the government, which is not available.

${ }^{13}$ This is not a complete list of economic theories that speak to the tradeoff between loyalty and competence. Prendergast and Topel (1996) show that a principal who values the power to affect his agent's welfare may prefer less competent agents, and Friebel and Raith (2004) posit that a manager may fear competent subordinates because they may wish to take his post. These models can explain an inverse relationship between loyalty and competence but have no other predictions that can be tested with the present data. The reason is that the Friebel and Raith model assumes that the middle manager chooses different hiring standards for his subordinates than top management uses for the middle manager. By contrast, in the present dataset, we have information only about the overall use of entrance exams for the most important positions in agencies. The Prendergast and Topel model is also more about the misallocation of talent within organizations rather than about the overall level of talent.
} 


\section{Data and methodology}

Measuring the concepts that feature in the theoretical models is difficult, and any measurement is likely to be incomplete at best. Still, a dataset compiled and thankfully made publicly available by Evans and Rauch (1999) and Rauch and Evans (2000) contains a rich set of variables that allow an econometric analysis of the above relationships. Detailed information on the dataset is provided in the codebook (available for download at http://weber.ucsd.edu/ jrauch/webstate/) and in the original papers. The Appendix to this paper contains the country list and a mapping of my variables to the Evans and Rauch data.

Evans and Rauch constructed their data from questionnaires sent to country experts in 35 semi-industrialized nations. Experts were first asked to name the most important agencies in their country. ${ }^{14}$ The experts then answered questions concerning the hiring mechanisms, career perspectives, etc. The experts did not disaggregate their answers according to the various agencies, but rather referred to "these agencies" in all their answers. Each variable is categorical for individual expert answers, but Evans and Rauch average the answers of country experts so that the data are close to continuous for most variables.

The rationale for using this sample is similar to that of Evans and Rauch (1999: 754). An advantage of studying the countries at hand is that it is a relatively homogenous sample that allows studying variation in agency competence among semi-industrialized countries rather than between developing and advanced industrial countries. Also, there is likely to be more variation in the relevant variables among semi-industrialized countries than among industrialized countries. Despite the appeal of using this dataset, however, the results should be interpreted as carefully as those of other cross-country studies with limited samples.

\subsection{Dependent variable}

Individual competence of high-level executives is not measured in the data. However, experts provided information on what proportion of the higher officials in the agencies enter the civil service via a formal examination system. The variable EXAMS contains this information. Of course, it is not entirely obvious that the extent of the prevalence of formal civil service examinations increases individuals' competencies. But it seems likely that it at least shifts the distribution in the right direction. As an alternative variable, I use UNIVERSITY which measures the education of those that do not enter through examinations. Information on how selective exams are (e.g., the pass rate) is not included in the data.

\subsection{Key explanatory variables}

I measure officials' temptations for disloyalty in two ways. The first measure for side opportunities is given by PRIVATESECTOR, which measures how common it is for higher officials in these agencies to spend substantial proportions of their careers in the private sector. The rationale for using this variable derives from the notion that in countries where private and public sector activities are significantly interspersed, more competent officials

\footnotetext{
${ }^{14}$ In total, 126 experts participated in the study. The number of expert survey respondents per country varies and is reported in Rauch and Evans (2000: 69). See the Appendix for the instructions given to the experts. Ranked by their average importance (between 1 and 4) as determined by the experts, the agencies are: Ministry of Finance, 3.11, Planning Ministry, 1.94, President's or Prime Minister's Office/Royal Palace, 1.60, Central Bank, 1.57, Trade Ministry, 1.49, Other, 1.09, Ministry of Economics, 0.71, Monetary Authority, 0.23 , Defense Ministry, 0.20.
} 
are more able to leverage their skills in current side activities or in future outside activities, thus increasing officials' payoffs on the reneging path. I also use PRIVATE-RETIRE in a robustness test. This variable measures how common it is for higher officials to have significant post-retirement careers in the private sector.

Second, agency officials can engage in illegal activities and collect bribes or other extra income. The Evans and Rauch data contain information on how legal salaries compare to private sector salaries (RELATIVE SALARY) as well as how total income (legal plus illegal income) compares to the private sector (RELATIVE SALARY WITH BRIBES). These comparisons are not given in monetary terms but in terms of ranks, but they are still informative. The difference between these two variables, BRIBES, gives an (approximate) measure of the side opportunities. Note that BRIBES does not measure loyalty or disloyalty (as a behavior); rather, it measures the opportunity cost of loyalty. More competent officials plausibly have more side opportunities, and these are opportunities the official can engage in while remaining employed at the agency. Some of these illegal activities may be avoided by having explicit laws against them, and it is likely that the countries are doing what they can to limit corruption. But imperfect law enforcement makes it plausible that at least some part of side opportunities remains that cannot be contracted away; indeed, BRIBES is almost always strictly positive in the sample. ${ }^{15}$ As a proxy for discounting, SHORTTIMEHORIZON measures the modal number of years spent by a typical higher level official in the agencies over his career. This variable, which henceforth is abbreviated as $S H O R T$, is equal to 1 when the time horizon is shorter than 10 years, and 0 when it is longer than 10 years. TIMEHORIZON is a variable that splits these two groups into two additional groups each, resulting in four categories (1-5 years, 5-10 years, 10-20 years, 20 years or longer). The results are robust to using this definition.

Finally, measuring the value of loyalty is perhaps the most challenging task, and I recognize the limitations any proposed measure must bring with it. In line with the theoretical discussion above, the value of loyalty to the government is at least co-determined by the costs of securing policy alignment. This suggests that an appropriate measure of the value of loyalty is the power of agencies. I use two variables: First, POWER measures how likely it is that ideas and policies initiated by the agencies prevail. According to the experts' opinions, no agency in the sample can prevail against the explicit will of the government; however, it costs the top executive political capital to force a decision.

Second, I create an interaction term between POWER and a measure of how many policies the agency is in fact responsible for (POLICIES). Intuitively, if an agency is responsible for many issues and can hold up the government when it withholds its approval, the loyalty of the agency executive and his staff is important. This interaction term then constitutes my variable VALUE OF LOYALTY, which henceforth is abbreviated as LVALUE. The main analysis is conducted with $L V A L U E$, but all the results also hold if I use POWER instead.

\footnotetext{
${ }^{15}$ One theoretical concern might be the following: If one aspect of loyalty is the absence of bribes, and we still observe a positive level of bribes in the data, does that not imply that agents do not act loyally? After all, all the models' predictions above are equilibrium predictions that apply when the principal obtains at least partial loyalty. There are several responses to this issue. First, loyalty has multiple dimensions, only one of which is the absence of bribes. Second, the very presence of bribes suggests that it is difficult to get rid of them with laws (which are in place in virtually all of the countries analyzed). Where the temptation for accepting bribes is higher, they will be accepted, thus inducing the need for lower competence in order to somewhat limit, but not extinguish, bribery. Of course, if the governing regime itself is corrupt, then corruption on the part of agencies may be an act of loyalty.
} 


\subsection{Control variables}

I also control for additional variables that do not play an explicit role in the theoretical model but can be hypothesized to affect the choice of recruiting systems in public agencies. First, I employ a measure of the size of the pool of competence from which agency officials can be drawn. For this, I use a proxy for human capital in the economy. If we did not control for human capital, that would be an easy explanation for why an agency just cannot use civil service exams to select between potential officials. I use the standard measure for educational attainment, the Barro and Lee (1993) measure of the average schooling years in the total population over age 25 . In the tables presented here, I use educational attainment from 1970, but the results are not substantively affected if I instead use the numbers from 1990. It would be nice to control for the fungibility of human capital in agencies (for example, the proportion of lawyers). Unfortunately, this information is not readily available for a sufficiently large sample of countries.

Not all countries have the same history of using civil service exams. While all countries except Argentina have had civil service examinations in place since the 1970s at the latest, there is some variation in countries' length of experience with this governance tool. Thus, I control for a variable (from Evans and Rauch's experts) that summarizes this history, HISTORYCIVIL. I expect that countries with a longer history of using civil service exams generally are also more likely to use these exams for the higher positions in agencies.

To further minimize the problem that the regressions may be picking up other country fixed effects, I also include a measure of the country's development, namely, GDP per capita, from the Penn World Tables. The regressions in the paper use the level from 1970, but the results hold if I instead use data from 1990 as well.

Moreover, I control for how many of the top levels in the agencies are in fact political appointees $(P O L A P P)$. It is likely that a country with more political appointees is more resistant to an exams-based system.

\subsection{Descriptive statistics}

Descriptive statistics for all variables are contained in Table 1 (at the end of the paper).

A few observations are in order. First, all of the agencies that Evans' and Rauch's experts provided data for are important in the sense that none of them just implements policy dictated from above. Second, without exception, in all agencies, there is at least some degree of political appointment of executives and high officials; often, this goes even into the second and third levels of the hierarchy. ${ }^{16}$

\subsection{Estimation strategy and limitations}

The generic regression I run is the following:

$$
\begin{aligned}
\text { EXAMS }_{i}= & a+b * \text { LVALUE }_{i}+c * \text { SHORT }_{i}+d *\left(\text { LVALUE }_{i} * \text { SHORT }_{i}\right) \\
& +e * \text { OUTSIDEOPTIONS }_{i}+f *\left(\text { OUTSIDEOPTIONS }_{i} * \text { SHORT }_{i}\right) \\
& +g * \text { CONTROLS }_{i}
\end{aligned}
$$

\footnotetext{
${ }^{16}$ These two facts can be seen from noting that the minimum values of the variables "Number of policies" and "Extent of political appointment" are 2, not 1.
} 
Table 1 Descriptive statistics

\begin{tabular}{|c|c|c|c|c|c|}
\hline Variable & Obs & Mean & $\begin{array}{l}\text { Std. } \\
\text { Dev. }\end{array}$ & Min & Max \\
\hline EXAMS: Formal exams for high officials & 35 & 2.17 & 1.00 & 1.00 & 4.00 \\
\hline POLICIES: Number of policies originating in agencies & 35 & 2.27 & 0.43 & 1.50 & 3.00 \\
\hline POWER: Power of agencies & 35 & 1.95 & 0.26 & 1.33 & 2.40 \\
\hline LVALUE: Value of loyalty & 35 & 4.46 & 1.20 & 2.44 & 6.24 \\
\hline SHORT: Short time horizon & 35 & 0.43 & 0.50 & 0.00 & 1.00 \\
\hline Value of loyalty $*$ Short time horizon & 35 & 1.95 & 2.46 & 0.00 & 6.24 \\
\hline HISTORYCIVIL: History of civil service & 35 & 4.19 & 0.98 & 1.00 & 6.00 \\
\hline POLAPP: Extent of political appointment & 35 & 3.11 & 0.59 & 1.50 & 4.00 \\
\hline PRIVATESECTOR: Private sector contacts & 35 & 2.46 & 0.89 & 1.00 & 4.00 \\
\hline BRIBES: Extra income from bribes etc. & 35 & 1.06 & 0.97 & -0.50 & 2.83 \\
\hline Extra income from bribes * short time horizon & 35 & 0.46 & 0.89 & -0.50 & 2.67 \\
\hline GDP per capita 1970 & 35 & 2422.49 & 1502.31 & 586.00 & 6004.00 \\
\hline Human capital 1970 & 35 & 3.36 & 1.74 & 0.90 & 7.62 \\
\hline
\end{tabular}

Note: Variables in CAPITAL letters are from Evans and Rauch (1999) and Rauch and Evans (2000). The other variables are created as described in the Appendix. GDP p.c. is from the Penn World Tables, and human capital is from Barro and Lee (1993)

where OUTSIDEOPTIONS are either PRIVATESECTOR or BRIBES and where CONTROLS comprise available human capital in the economy, level of development, the history of civil service exams, and the extent of political appointment. Being the average of opinions, $E X$ $A M S$ has many categories, and so I employ OLS estimation with heteroscedasticity consistent standard errors. In the above regression, Wagner's (2006) model leads us to expect $b>0, c<0, d<0, e<0, f>0$, Egorov and Sonin's (2006) model implies $b<0, c<0$, Glazer's (2002) model implies $b<0$, and the contractible loyalty model implies $b>0$.

I highlight for the reader a limitation of this empirical approach. Because of the crosssectional nature of the data, addressing endogeneity is very difficult. If we had time-series data, we could employ a fixed effects estimator to address the potential concern of an omitted variable bias, but such data are not available. Of course, the cleanest approach to clarifying causality would be an instrumental variables estimation. This would require the availability of a valid instrument, i.e., an exogenous variable that affects, for example, the value of loyalty, but has no effect on competence in agencies through other channels except for its effect on the value of loyalty. But such a variable is very hard to find. ${ }^{17}$ While this limitation is not to be taken lightly, one might first note that the first generation of the empirical literature on economic growth proceeded along these lines even though the authors at the time were, of course, also aware of the limitations of their approach. Second, and less defensively, the importance of the question of what factors are associated with competence in public agencies compels the researcher to use data to make the best inferences possible with them. At the very least, therefore, the paper provides novel evidence on the correlations between relevant

\footnotetext{
${ }^{17}$ I report results with legal origin as a potential instrumental variable in the text below, but on theoretical grounds, this seems a problematic instrument, even if the empirical effects in the second stage regression come out nicely. After all, it is quite possible that legal origin is related directly to different types of recruitment in different countries.
} 
Table 2 Correlations between the dependent variable and key explanatory variables

\begin{tabular}{lrrrrr}
\hline & \multicolumn{1}{l}{ 1 } & \multicolumn{1}{l}{3} & 4 & 5 \\
\hline EXAMS: Formal exams & 1.000 & & & & \\
LVALUE: Value of loyalty & $\mathbf{0 . 1 6 0}$ & 1.000 & & & \\
SHORT: Short time horizon & $\mathbf{- 0 . 3 0 9}$ & 0.070 & 1.000 & & \\
PRIVATESECTOR: Private sector contacts & $\mathbf{- 0 . 5 2 1}$ & -0.111 & 0.471 & 1.000 & \\
BRIBES: Extra income through bribes & $\mathbf{- 0 . 4 1 4}$ & -0.397 & -0.023 & 0.057 & 1.000 \\
\hline
\end{tabular}

factors of the institutional setup of economies, even if one wishes to abstain from making statements about causality. Third, the fact that some of the explanatory variables of interest are interaction terms makes it far less plausible that the estimates for these variables are confounded by endogeneity.

\section{Findings}

Since the non-contractible loyalty model provides the most stringent set of hypotheses testable with the data, this section organizes the evidence around this model's predictions.

I begin by considering partial correlations of the variables of interest. These can be found in Table 2, where the most relevant correlations highlighted in bold face.

As predicted, the value of loyalty and the time horizon are positively correlated with competence, while outside opportunities (as measured by private sector contacts and extra income through bribes) are negatively correlated with competence. Notably, though, for short time horizons, the correlation of the value of loyalty and competence is virtually zero, while it is strongly positive for long time horizons; moreover, the effect of bribes is more pronounced when interactions are long. I next test the predictions concerning the joint effects of importance of loyalty, outside opportunities, and the time horizon in a regression framework.

Consider Table 3. While the first column shows that the value of loyalty is not significantly related to competence on its own, the effect becomes positive and significant, consistent with hypothesis (C), once we control for other variables as we move to the right in the table, suggesting that the omission of those variables had biased downwards the coefficient for LVALUE in the first column.

Column (2) indicates that, consistent with hypothesis (B), relatively short-term interactions are associated with lower competence levels. Moreover, according to columns (3) and (4), the interaction effect between the value of loyalty and impatience has a negative sign, which is consistent with hypothesis (E). Thus, overall, for a short time horizon, the value of loyalty is negatively associated with the level of competence. The theory predicts that where interactions are too short to establish loyalty with competent agencies, governments need to sacrifice competence in order to secure adequate levels of loyalty, and this prediction is borne out in the data. The short time horizon dummy itself has a positive sign in these two regressions, but when taking into account the interaction with the value of loyalty, the overall marginal effect, evaluated at the mean, is negative, as predicted, and is statistically significant.

As for the control variables, as expected, richer countries and those who have had civil service exams in place for a longer period of time choose more stringent access rules to the higher echelons of government. Finally, column (4) shows that, as expected, political 
Table 3 Competence in public agencies, the importance of loyalty, and the time horizon. Dependent variable: EXAMS: Extent of formal examinations for high positions in civil service

(1)

LVALUE: Value of loyalty (\#policies * power)

SHORT: Short time horizon

Value of loyalty $*$ short time horizon

POLAPP: Extent of political appointment

of high officials

HISTORYCIVIL History of civil service exams

GDP p.c. 1970

Hunan capital 1970

Constant

Observations

$R$-squared

Notes: Robust $t$ statistics in parentheses.

**** significant at 1 percent

(2)

(3)

(4)

$-0.012$

(0.09)

$\begin{array}{cccc} & -0.618 & 2.190 & 2.122 \\ & (2.02)^{*} & (1.66) & (2.15)^{* *} \\ & & -0.609 & -0.572 \\ & & (2.40)^{* *} & (2.95)^{* * *} \\ & & & -0.498 \\ & & & (1.96)^{*} \\ & & & 0.590 \\ 0.666 & 0.614 & 0.633 & (3.89)^{* * *} \\ (5.34)^{* *} & (4.32)^{* * *} & (3.99)^{* * *} & 0.000 \\ 0.000 & 0.000 & 0.000 & (3.13)^{* * *} \\ (1.96) & (1.81)^{*} & (2.42)^{* *} & -0.005 \\ 0.063 & 0.071 & 0.031 & (0.06) \\ (0.68) & (0.65) & (0.30) & 3.478 \\ 3.501 & 3.635 & 1.868 & (3.03)^{* * *} \\ (4.03)^{* *} & (6.75)^{* * *} & (2.19)^{* *} & 35 \\ 35 & 35 & 35 & 0.70 \\ 0.43 & 0.52 & 0.63 & \text { percent }\end{array}$

appointment and (more or less objective) civil service exams are incompatible. The coefficients on the value of loyalty and the interaction between the value and impatience retain the predicted sign also with this control. This forms the preferred specification for further analysis.

This evidence already helps us to distinguish some theories. Glazer (2002) and Egorov and Sonin (2006) predict a negative relationship between LVALUE and EXAMS, while the data show a positive relationship, more consistent with Wagner (2006). Both Egorov and Sonin (2006) and Wagner (2006) predict a negative relationship between SHORT and EX$A M S$, as is observed in the data, while Glazer (2002) does not.

The findings so far could also be evidence for an alternative story, namely, that the government and the agencies' officials can contract on loyalty and that loyalty and competence are complements in production, i.e., that the value of loyalty is positively related to an agencies' competence. Thus, we would also see a positive correlation between LVALUE and EXAMS. In other words, an unobserved variable such as the "production technology" of the country could be driving the correlation, or there may be reverse causality. One answer to this challenge is that even observing the correlation in the data is informative.

However, we can also make additional statements that cast some doubt on the alternative interpretations. First, on theoretical grounds it is hard to see how loyalty of the sort relevant here can be contracted upon in a court-enforceable way. Second, the results also hold when the measure of the value of loyalty is POWER instead of LVALUE, and POWER would also seem to be affected only to a small extent by the competence of the agency officials. Third, the interaction term between LVALUE and SHORT is unlikely to be affected by endogeneity, 
Table 4 Competence in public agencies and predictions regarding the availability of outside options. Dependent variable: EXAMS: Extent of formal examinations for high positions in civil service

(5)

$-0.395$

PRIVATESECTOR: Outside options

$(2.01)^{*}$

BRIBES: Extra income from bribes etc.

Extra income from bribes * short time horizon

LVALUE: Value of loyalty (\#policies * power)

SHORT: Short time horizon

Value of loyalty * short time horizon

POLAPP: Extent of political

appointment of high officials

HISTORYCIVIL: History of civil service exams

GDP p.c. 1970

Human capital 1970

Constant

Observations

$R$-squared

Robust $t$ statistics in parentheses. ${ }^{*}$ significant at 10 percent; ${ }^{* *}$ significant at 5 percent; ${ }^{* * * *}$ significant at 1 percent

but it is significant and goes in the direction predicted by the theory. Of course, as mentioned earlier, we would ideally approach the issue with an instrumental variables approach. Unfortunately, it is very hard to come up with a valid instrument. Legal origins (see La Porta et al. 1997a, 1997b, 1998), for example, work well from a statistical point of view-they are highly significant in the first stage, and the significance of $L V A L U E$ is retained in the second-stage regression. However, on economic grounds it is simply not plausible that legal origins affect agency competence only through the importance of agency loyalty.

There is yet another way in which to make progress. In particular, the theory fortunately has additional predictions which relate to the role of side opportunities and which do not follow from a multi-tasking model or a model where competence is just a factor in producing loyalty as the output. These joint predictions are tested in Table 4. Testing multiple predictions at the same time is, even in the presence of potential endogeneity of some of the variables, a much more difficult hurdle to clear for any theory.

Column (5) in Table 4 shows that the availability of outside options, as measured by private sector contacts, significantly reduces the government's optimal competence level (hypothesis (A). This result also holds when using instead the possibility of a career in the 
private sector after retirement (not shown). Note that the value of loyalty retains the positive sign in all regressions.

Another measure of the availability of side opportunities is the income differential between salary and salary including bribes and the difference between public and private sector salaries. Unreported results available on request indicate that high legal pay in the public sector relative to the private sector tends to be associated with more competent agency officials, but that where salary including bribes is high, less competent officials are observed. In some specifications there is also a negative effect of available illegal income on optimal competence. In the main specification reported here, this direct effect is not significant, as shown in column (6). Interestingly, though, column (7) shows that the prediction (D) concerning the interaction between side opportunities and the time horizon is borne out in the data, and, in fact, very strongly so. These results are important because a simple negative correlation between the availability of extra income in the public sector and competence would also arise in a model where agency officials are paid their marginal product in both the private and public sectors but can receive fixed amounts of bribes in the public sector. That model would, however, not predict the interaction effects between side opportunities and the time horizon.

\subsection{Robustness}

The results also hold for an alternative dependent variable. In particular, they hold with the proportion of those who do not enter via examinations but have university or post-graduate degrees.

Omitting the variable measuring the history of the existence of civil service exams does not materially change the results. (The results for side opportunities become more significant, while the results for the value of loyalty become less significant.)

As mentioned earlier, the findings also hold controlling for GDP per capita in 1990 or human capital in 1990. Given that the regressions control for several important country variables, the effects found over and above this effect can most likely be attributed to the tradeoff between loyalty and competence, especially because the theory is fairly specific in its predictions.

The results also hold for an alternative proxy for the duration of the interaction, namely, the extent of political dependence. This variable measures whether incumbents of top positions are likely to be moved to positions of lesser importance when leadership changes. This measure is only informative for countries where there is a sufficient turnover in chief executives.

Controlling for legal origin also does not change the results and is also not a significant explanatory variable in itself. Including measures of corruption (from various sources: Transparency International, La Porta et al. 1997a, 1997b, and Kaufmann et al. 2009) as a control variable does not affect the results. (It cannot be used in the regression which includes the level of bribes because these two variables are highly correlated. Corruption as a proxy for outside opportunities also fares well in the regressions, with the predicted results.)

Unfortunately, insufficient data are available to analyze competence across agencies in the same country. This would be a fruitful area for future research. In the present analysis, putting in dummies that capture which agency was regarded as the most important in various countries does not substantially affect the results. 


\section{Conclusion}

This paper has tested various theories of competence in public agencies, with a particular emphasis on a notion recently analyzed by Glazer (2002), Egorov and Sonin (2006) and Wagner (2006), namely, that under some circumstances there is a tradeoff between loyalty and competence. Using data from public agencies in a cross-section of countries, the paper finds the following evidence: Higher competence of agency officials is observed (1) when agency loyalty is arguably more important to the government, (2) when the time horizon for the interactions between the government and agency officials is longer, and (3) when outside options for agency officials are worse. Moreover, competence is lower (4) when loyalty is important but simultaneously the time horizon is short, and (5) when outside opportunities improve but simultaneously the time horizon is long. While not all of these results hold significantly in all regressions, overall, this evidence is most consistent, or at least not inconsistent, with a model of non-contractible loyalty. Alternative models either have differing predictions that are rejected in the data or can explain only subsets of these predictions. Notably, although the statistical analysis for each individual regression is not completely free from concerns regarding endogeneity, the joint evidence across several explanatory variables appears less likely to be affected by this problem. Nonetheless, other tests and applications can and should be considered. For example, it would be interesting to analyze intra-agency hiring policies, but for this, richer data from within agencies is needed. Also, time-varying data would greatly help. For example, countries which value meritocracy may also value high loyalty, and a panel setup could aid in filtering out unobserved variables and in (statistically) identifying the effects discussed in this paper. Thus, while the results in this paper are suggestive, further research can certainly improve our understanding not only of appropriate ways of modeling loyalty and competence but also of how countries do (and should) allocate competence within the public sector.

Acknowledgements I would like to thank the Editor (William F. Shughart II) and two anonymous Reviewers for excellent comments that greatly helped improve the paper. My thanks go in particular to Richard Zeckhauser for constant support throughout my graduate studies. Useful comments were provided by Philippe Aghion, Alberto Alesina, Charles Cohen, Kai Konrad, Francesco Trebbi, and Richard Zeckhauser, as well as seminar participants at George Mason University, Harvard, MIT, the University of Chicago, the University of Munich, and the University of Zurich. I thank the Swiss Finance Institute, the University Research Priority Program Finance and Financial Markets, and the NCCR FINRISK for financial support.

\section{Appendix}

\section{A.1 Countries}

Argentina, Brazil, Chile, Colombia, Costa Rica, Cote d'Ivoire, Dominican Republic, Ecuador, Egypt, Greece, Guatemala, Haiti, Hong Kong, India, Israel, Kenya, (South) Korea, Malaysia, Mexico, Morocco, Nigeria, Pakistan, Peru, Philippines, Portugal, Singapore, Spain, Sri Lanka, Syria, Taiwan, Thailand, Tunisia, Turkey, Uruguay, Zaire.

\section{A.2 Data on agencies}

This data comes from Evans and Rauch (1999) and Rauch and Evans (2000). Respondents to these authors' survey were told: "We are interested primarily in what these bureaucracies looked like in the recent past, roughly 1970-1990. In answering the following questions, assume that "higher officials" refers to those who hold roughly the top 500 positions in the core economic agencies [we discussed above]." 
EXAMS

UNIVERSITY

POWER

POLICIES

LVALUE (VALUE OF

LOYALTY)

SHORT

(SHORTTIMEHORIZON)

TIMEHORIZON

POLAPP

PRIVATESECTOR

PRIVATE-RETIRE

RELATIVE SALARY
Approximately what proportion of the higher officials in these agencies enter the civil service via a formal examination system? $1=$ less than $30 \%, 2=30-60 \%, 3=60-90 \%, 4=$ more than $90 \%$

Of those that do not enter via examinations, what proportion have university or post-graduate degrees?

$1=$ less than $30 \%, 2=30-60 \%, 3=60-90 \%, 4=$ more than $90 \%$

How likely are ideas and policies initiated by these agencies to prevail? $1=$ no more likely than ideas coming out of other parts of the state bureaucracy

$2=$ quite likely, even in the face of opposition from other parts of the bureaucracy, as long as the chief executive is neutral or supportive $3=$ under the circumstances above and also sometimes even in the face of opposition from the chief executive

Which of the following descriptions best fits the role of these agencies? $1=$ they rarely originate new policies, but are important in turning policies that originate in the political arena into programs that can be implemented

$2=$ some new policies originate inside them and they are important "filters" for policy ideas that come from political parties, private elites and the chief executive, often reshaping these ideas in the process $3=$ many new economic policies originate inside them

POWER * POLICIES (This variable is calculated for the present study)

What is roughly the modal number of years spent by a typical high level official in one of these agencies during his career?

$1=1-10$ years, $0=10$ years to entire career

What is roughly the modal number of years spent by a typical high level official in one of these agencies during his career?

$1=1-5$ years, $2=5-10$ years, $3=10-20$ years, $4=$ entire career

Roughly how many of the top levels in these agencies are political appointees (e.g., appointed by the President or Chief Executive)

$1=$ none, $2=$ just agency chiefs, $3=$ agency chiefs and vice chiefs,

$4=$ all of top 2 or 3 levels

How common is it for higher officials in these agencies to spend substantial proportions of their careers in the private sector, interspersing private and public sector activity?

$1=$ normal, $2=$ frequent but not modal, $3=$ unusual, $4=$ almost never

How common is it for higher officials in these agencies to have significant post-retirement careers in the private sector?

$1=$ normal, $2=$ frequent but not modal, $3=$ unusual, $4=$ almost never

How would you estimate the salaries (and perquisites, not including bribes or other extra-legal sources of income) of higher officials in these agencies relative to those of private sector managers with roughly comparable training and responsibilities?

$1=$ less than $50 \%, 2=50-80 \%, 3=80-90 \%, 4=$ comparable, $5=$ higher 
RELATIVE SALARY

WITH BRIBES

BRIBES

HISTORYCIVIL
(Follow-up to RELATIVE SALARY): If bribes and other extra-legal perquisites are included what would the proportion be?

$1=$ less than $50 \%, 2=50-80 \%, 3=80-90 \%, 4=$ comparable, $5=$ higher

Difference between RELATIVE SALARY WITH BRIBES and

RELATIVE SALARY. (This variable is calculated for the present study.)

(Note: This question refers to the higher Civil Service more broadly, not just to the top 500 officials in the core agencies.) Since roughly what date have civil service examinations been in place? (reordered from the original survey)

$1=1990-, 2=1980-1989,3=1970-1979,4=1950-1969,5=$ $1900-1949,6=$ Pre-1900

POLDEP

Are the incumbents of these top positions likely to be moved to positions of lesser importance when political leadership changes?

$1=$ almost always, $2=$ usually, $3=$ sometimes, $4=$ rarely

\section{References}

Aucoin, P. (1990). Administrative reform in public management: paradigms, paradoxes, and pendulums. Governance, 3(1), 115-137.

Baron, D. P., \& Besanko, D. (1984). Regulation, asymmetric information, and auditing. RAND Journal of Economics, 15, 447-470.

Barro, R. J., \& Lee, J.-W. (1993). International comparisons of educational attainment. Journal of Monetary Economics, 32, 363-394.

Bendor, J., Taylor, S., \& van Gaalen, R. (1985). Bureaucratic expertise versus legistlative authority: A model of deception and monitoring in budgeting. American Political Science Review, 79, 1041-1060.

Borge, L.-E., Falch, T., \& Tovmo, P. (2008). Public sector efficiency: the roles of political and budgetary institutions, fiscal capacity, and democratic participation. Public Choice, 136(3-4), 475-495.

Brennan, G., \& Buchanan, J. M. (1980). The power to tax: Analytical foundations of a fiscal constitution. Cambridge: Cambridge University Press.

Breton, A. (1995). Organizational hierarchies and bureaucracies: An integrative essay. European Journal of Political Economy, 11, 411-440.

Caiden, G. (1988). The vitality of administrative reform. International Review of Administrative Sciences, 54(3), 331-358.

Chang, K. H., Figueiredo, R. J. P. d., \& Weingast, B. R. (2001). Rational choice theories of bureaucratic control and performance. In W. F. Shughart II, \& L. Razzolini (Eds.), The Elgar companion to Public Choice (pp. 293-309). Cheltenham: Edward Elgar.

Cohen, D. M. (1998). Amateur government. Journal of Public Administration Research and Theory, 8(4), 450-497.

Dittman, I. (1999). How reliable should auditors be? Optimal monitoring in principal-agent relationships. European Journal of Political Economy, 15, 523-546.

Downs, A. (1967). Inside bureaucracy. Boston: Little Brown.

Dunleavy, P. (1985). Bureaucrats, budgets, and the growth of the state: Reconstructing an instrumental model. British Journal of Political Science, 15, 299-328.

Dunleavy, P. (1991). Democracy, bureaucracy and public choice. London: Harvester Wheatsheaf.

Edwards, G. C. (2001). Why not the best? The loyalty-competence trade-off in presidential appointments. The Brookings Review, 19(2), 12-16.

Egorov, G., \& Sonin, K. (2006). Dictators and their viziers: Endogenizing the loyalty-competence trade-off. Mimeo, available at http://papers.ssrn.com/sol3/papers.cfm?abstract_id=630503.

Evans, P. (1995). Embedded autonomy: States and industrial transformation. Princeton: Princeton University Press.

Evans, P., \& Rauch, J. E. (1999). Bureaucracy and growth: A cross-national analysis of the effects of 'Weberian' state structures on economic growth. American Sociological Review, 64(5), 748-765.

Friebel, G., \& Raith, M. (2004). Abuse of authority and hierarchical communication. RAND Journal of Economics, 35(2), 224-244. 
Glazer, A. (2002). Allies as rivals: internal and external rent seeking. Journal of Economic Behavior and Organization, 48, 155-162.

Heclo, H. (1977). A government of strangers: Executive politics in Washington. Washington: Brookings Institution.

Kaufmann, D., Kraay, A., \& Mastruzzi, M. (2009). Governance matters VIII: Aggregate and individual governance indicators, 1996-2008. Mimeo, available at http://papers.ssrn.com/sol3/ papers.cfm?abstract_id=1424591.

Kofman, F., \& Lawarrée, J. (1993). Collusion in hierarchical agency. Econometrica, 61(3), 629-656.

Konrad, K. A., \& Torsvik, G. (1997). Dynamic incentives and term limits in bureaucracy regulation. European Journal of Political Economy, 13, 261-279.

La Porta, R., Lopez-de-Silanes, F., Shleifer, A., \& Vishny, R. (1997a). Legal determinants of external finance. Journal of Finance, 52(3), 1131-1150.

La Porta, R., Lopez-de-Silanes, F., Shleifer, A., \& Vishny, R. (1997b). Trust in large organizations. American Economic Review Papers and Proceedings, 333-338.

La Porta, R., Lopez-de-Silanes, F., Shleifer, A., \& Vishny, R. (1998). Law and finance. Journal of Political Economy, 106(6), 1113-1155.

Laffont, J.-J., \& Martimort, D. (1998). Collusion and delegation. RAND Journal of Economics, 29, 280-305.

Laffont, J.-J., \& Zantman, W. (2002). Information acquisition, political game and the delegation of authority. European Journal of Political Economy, 18, 407-428.

Makris, M. (2006). Political authority, expertise and government bureaucracies. Public Choice, 127(3-4), 275-292.

Miller, G. J., \& Moe, T. M. (1983). Bureaucrats, legislators, and the size of government. American Political Science Review, 77, 297-322.

Mueller, D. (2003). Public choice III. Cambridge: Cambridge University Press.

Niskanen, W. A. (1971). Bureaucracy and representative government. New York: Aldine-Atherton.

Niskanen, W. A. (2001). Bureaucracy. In W. F. Shughart II, \& L. Razzolini (Eds.), The Elgar companion to Public Choice (pp. 258-270). Cheltenham: Edward Elgar.

Prendergast, C., \& Topel, R. H. (1996). Favoritism in organizations. Journal of Political Economy, 104(5), 958-978.

Rauch, J., \& Evans, P. (2000). Bureaucratic structure and bureaucratic performance in less developed countries. Journal of Public Economics, 75(1), 49-71.

Rijckeghem, C. V., \& Weder, B. (2001). Bureaucratic corruption and the rate of temptation: do wages in the civil service affect corruption, and by how much? Journal of Development Economics, 65(2), 307-331.

Seabright, P. (1996). Accountability and decentralization in government: an incomplete contracts model. European Economic Review, 40, 61-90.

Tirole, J. (1986). Hierarchies and bureaucracies: On the role of collusion in organizations. Journal of Law, Economics, and Organization, 2(2), 181-214.

Tirole, J. (1992). Collusion and the theory of organizations. In J.-J. Laffont (Ed.), Advances in economic theory (Vol. 2). Cambridge: Cambridge University Press.

Tullock, G. (1965). The politics of bureaucracy. Washington: Public Affairs Press.

Vafaï, K. (2002). Preventing abuse of authority in hierarchies. International Journal of Industrial Organization, 20, 1143-1166.

Vafaï, K. (2005). Abuse of authority and collusion in organizations. European Journal of Political Economy, $21,385-405$.

Verwimp, P. (2003). The political economy of coffee, dictatorship, and genocide. European Journal of Political Economy, 19, 161-181.

Wagner, A. F. (2006). A model of loyalty and competence. Mimeo, available at http://www.isb.uzh.ch/institut/ staff/wagner.alexander/publications/.

Wilson, J. Q. (1989). Bureaucracy: What government agencies do and why they do it. New York: Basic Books.

Wintrobe, R. (1997). Modern bureaucratic theory. In D. Mueller (Ed.), Perspectives on public choice. Cambridge: Cambridge University Press.

Wintrobe, R. (1998). The political economy of dictatorship. Cambridge: Cambridge University Press.

Wise, L. R. (2004). Bureaucratic posture: On the need for a composite theory of bureaucratic behavior. Public Administration Review, 64(6), 669-680.

Wyckoff, P. G. (1990). The simple analytics of the slack-maximizing bureaucracy. Public Choice, 67, 35-47. 